Supplement of Ocean Sci., 13, 983-995, 2017

https://doi.org/10.5194/os-13-983-2017-supplement

(C) Author(s) 2017. This work is distributed under

the Creative Commons Attribution 4.0 License.

(c) (1)

Supplement of

\title{
Combining physical and geochemical methods to investigate lower halocline water formation and modification along the Siberian continental slope
}

Matthew B. Alkire et al.

Correspondence to: Matthew B. Alkire (malkire@ apl.washington.edu)

The copyright of individual parts of the supplement might differ from the CC BY 4.0 License. 


\section{Contents of this file}

Text $\mathrm{S} 1$ to $\mathrm{S} 2$

Tables S1 to S4

Figures $\mathrm{S} 1$ to $\mathrm{S} 4$

\section{Introduction}

The following supporting information includes text describing the instruments and methods used for data collection (Text S1) and the water type analysis used to estimate fractional contributions of meteoric water, net sea-ice meltwater, and Atlantic water to each discrete water sample collected during the 2013 and 2015 cruises (Text S2). Table S1 summarizes the winter mixed layer depths and estimates of the mean salinities and potential temperatures of the subsequent winter mixed layer. Additional tables summarize linear regressions of salinity and stable oxygen isotope ratio $\left(\delta^{18} \mathrm{O}\right)$ data in specified salinity ranges from the 2015 cruise (Tables S2 and S3) and additional data sets for comparison (Table S4). Figure S1 provides a schematic of salinity and $\delta^{18} \mathrm{O}$ changes that take place during the transition of halocline waters from the sea-ice melt branch mixing regime to the meteoric water branches as a result of mixing with overlying freshwaters, brine expulsion during ice formation, and mixing with underlying Atlantic waters. Figure $\mathrm{S} 2$ compares the salinity and $\delta^{18} \mathrm{O}$ data collected during the 2013 cruise data and used to define mixing relationships in the salinity range $34 \leq \mathrm{S}<34.5$ against the salinity and $\delta^{18} \mathrm{O}$ characteristics of lower halocline water types defined by Bauch et al., [2016]. Figures S3 and S4 provide vertical profiles of potential temperature and salinity from selected stations occupied during the 2013 cruise. 
Text S1. Full description of instrumentation and water sampling methods employed during the 2013 and 2015 cruises.

The sensor suite utilized during the 2013 and 2015 cruises included a Seabird SBE9plus conductivity-temperature-depth (CTD) equipped with dual temperature (SBE3), conductivity (SBE4), and dissolved oxygen (SBE43) sensors, SBE5T submersible pump, and a digi-quartz pressure sensor. Additional channels of the CTD system were directly connected to external sensors mounted on the carousel, including a WET Labs ECO-FLNTU chlorophyll and turbidity sensor, a WET Labs C-Star transmissometer (beam transmission and attenuation), a photosynthetically-active radiation (PAR) sensor (Biospherical model QCP2350), and a Satlantic Deep Submersible Ultraviolet Nitrate Analyzer (SUNA). A Benthos PSA-916 altimeter was also mounted to the bottom of the rosette to avoid hitting the carousel on the seafloor. Finally, twenty-four Niskin bottles (10 L capacity) were included for the collection of water samples at specified depths. All instruments were levelly mounted in the bottom section of the carousel directly below the Niskin bottles. Data was monitored and acquired during each cast using a Seabird SBE11plus Deck Unit.

During each cast, the rosette was moved outside to the starboard (2013) or port side (2015) deck from either a warmed container on deck using a wheeled cart (2013) or from the hydrology lab inside the ship using a hydraulic crane (2015). The rosette was then transferred to a winch and lowered over the side of the vessel to a depth of $\sim 15 \mathrm{~m}$ for initialization and sensor equilibration. The rosette was then brought up to the surface (0-3 $\mathrm{m})$ and then lowered through the water column at a relatively constant rate to a depth of either $\sim 1000 \mathrm{~m}$ or between 5 and $20 \mathrm{~m}$ above the bottom (most casts were conducted to $\sim 1000 \mathrm{~m}$ as some instruments cannot withstand pressures exceeding $1000 \mathrm{db}$ ). Once the maximum depth was reached, the rosette was stopped and a Niskin bottle was fired to obtain a water sample. The rosette was then brought back up through the water column and routinely stopped at depths of 500, 250, 200, 150, 140, 130, 120, 110, 100, 90, 80, $70,60,50,40,30,20,10$, and $2-4 \mathrm{~m}$ (surface) for the collection of water samples (alternate or additional depths were tripped on a cast-by-cast basis). The rosette was stopped for a period of $\sim 30$ seconds before sample collection to allow the bottles to soak and minimize turbulent flows caused the carousel's wake as it moved upward through the water column. Once the rosette reached the surface, it was brought back on deck and transferred inside the hydrology lab using the crane.

Salinity samples were collected into $125-\mathrm{mL}$ glass bottles equipped with polyethylene inserts to prevent evaporation. In 2013, salinity samples were analyzed via salinometer onboard after a 12-hour temperature equilibration. However, unstable laboratory temperatures prevented the collection of quality data from the salinometer; thus, the bottle salinity data was not utilized from the 2013 cruise. In 2015, bottle samples $(n=93)$ for salinity determinations were collected and shipped back to the University of Washington for analysis using a Guideline $8400 \mathrm{~B}$ salinometer (calibrated with IAPSO standard seawater) at the Marine Chemistry Laboratory (UW Oceanography). The majority (76\%) of bottle salinities differed from CTD salinities by $\leq 0.04$, though larger discrepancies did occur (49\% of available comparisons indicated differences of $\leq 0.01$ and $86 \%$ indicated differences $\leq 0.1)$. 


\section{Text S2: Full description of water type analysis methods.}

Fractional contributions of meteoric water (MW) and net sea-ice meltwater (SIM), and a saline water endmember (Atlantic seawater, AW, for the purposes of this study) can be quantified using salinity and $\delta^{18} \mathrm{O}$ observations in a set of coupled equations that also conserves mass (or volume):

$$
\begin{aligned}
& S_{\text {SIM }} \times f_{\text {SIM }}+S_{\text {MW }} \times f_{M W}+S_{\text {AW }} \times f_{A W}=S_{\text {obs }} \\
& \delta^{18} \mathrm{O}_{\text {SIM }} \times f_{\text {SIM }}+\delta^{18} O_{M W} \times f_{M W}+\delta^{18} O_{\text {AW }} \times f_{A W}=\delta^{18} O_{\text {obs }} \\
& f_{\text {SIM }}+f_{M W}+f_{A W}=1
\end{aligned}
$$

where $f$ equals the fractional contributions of the three water types (i.e., SIM, MW, and AW) and $S$ and $\delta^{18} \mathrm{O}$ represent the characteristic salinities and stable oxygen isotopic ratios associated with these water types. Note that net sea-ice formation (formation exceeding melting) will generate a negative SIM fraction $\left(\mathrm{f}_{\mathrm{SIM}}<0\right)$, representing an extraction of liquid water into the solid phase (ice) and the release of brine into the water column. This water type analysis assumes that salinity and $\delta^{18} \mathrm{O}$ values that characterize MW, SIM, and AW (commonly referred to as endmember values) are well known and relatively stable over time. However, there is seasonal and interannual variability associated with these endmember values that should be taken into account when conducting a water type analysis. Thus, estimates of uncertainty in the water type fractions resulting from the analysis can be computed by varying the endmember values within reasonable ranges of natural variability. In this study, meteoric water $\delta^{18} \mathrm{O}$ endmember values were varied between -22 and $-18 \%$. The salinity of meteoric water is zero by definition. Sea-ice meltwater salinity and $\delta^{18} \mathrm{O}$ endmember values were varied between 2 and 8 and -2 and $+3 \%$, respectively. Atlantic seawater salinity and $\delta^{18} \mathrm{O}$ endmember values were varied between 34.85 and 35 and 0.25 and $0.35 \%$, respectively.

Similar to the methods described in Alkire et al. [2015], the water type analysis was iterated 1,000 times for each salinity and $\delta^{18} \mathrm{O}$ pair. The set of endmember values characterizing MW, SIM, and AW were randomly selected from the specified ranges for each iteration. Though the endmember selection was randomized, it was organized in such a way that allowed all values within each range to be selected an equal number of

times. Averages of the MW, SIM, and AW fractions (1,000 values for each salinity, $\delta^{18} \mathrm{O}$ pair) were taken as the best estimate of the water type fractions and associated standard deviations taken as estimates of uncertainties due to natural variations in the endmember assignments. The median standard deviations for MW, SIM, and AW fractions were $0.24,0.36$, and $0.20 \%$ for the 2013 cruise and $0.29,0.41$, and $0.21 \%$ for the 2015 cruise, respectively. Note that these uncertainties are absolute uncertainties (e.g., meteoric water fraction reported as $8 \pm 0.24 \%$ ). 
Table S1. Winter mixed layer (WML) depth, salinity, and potential temperature $(\theta)$ estimated from CTD data by identifying the minimum potential temperature below the surface mixed layer. We note that the identification of the WML depth by this method is associated with some uncertainty and may be particularly ambiguous at stations with a mixed layer close to the freezing point. The WML depths estimated using this method were visually checked against vertical profiles of potential temperature and $\theta-S$ diagrams.

Stations that appeared to have no clearly identifiable $\theta_{\min }$ or multiple minima are marked with " $C N D$ " (could not determine). "Salt mixed" and " $\theta$ mixed" refer to the mean salinities and potential temperatures estimated from individual profiles assuming the water column will be homogenized down to the previous year's WML.

\begin{tabular}{|c|c|c|c|c|c|c|}
\hline Station & Transect & WML Depth (m) & WML Salinity & WML $\theta$ & Salt mixed & $\theta$ mixed \\
\hline 1 & - & 52 & 34.556 & -0.699 & 34.112 & 1.009 \\
\hline 2 & - & 56 & 34.368 & -1.674 & 33.867 & -1.317 \\
\hline 3 & - & 45 & 34.365 & -1.384 & 33.876 & -1.277 \\
\hline 4 & - & 52 & 34.414 & -1.533 & 33.849 & -1.501 \\
\hline 5 & - & 49 & 34.443 & -1.485 & 33.563 & -1.240 \\
\hline 6 & - & 48 & 34.236 & -1.663 & 32.940 & -0.403 \\
\hline 7 & L5 & $C N D$ & - & - & - & - \\
\hline 8 & L5 & $C N D$ & - & - & - & - \\
\hline 9 & L5 & 85 & 34.282 & -1.659 & 33.084 & -0.417 \\
\hline 10 & L5 & 87 & 34.317 & -1.611 & 33.350 & -0.631 \\
\hline 11 & L5 & 58 & 34.024 & -1.750 & 32.457 & -0.503 \\
\hline 12 & L5 & 50 & 33.893 & -1.792 & 32.896 & -1.097 \\
\hline 13 & L5 & 64 & 33.896 & -1.799 & 32.744 & -1.272 \\
\hline 14 & L5 & 56 & 33.918 & -1.797 & 32.947 & -1.486 \\
\hline 15 & L5 & 52 & 34.023 & -1.775 & 33.315 & -1.611 \\
\hline 16 & L5 & 67 & 34.210 & -1.727 & 33.573 & -1.667 \\
\hline 17 & L5 & 53 & 33.968 & -1.762 & 33.141 & -1.653 \\
\hline 18 & L5 & 52 & 34.149 & -1.721 & 33.285 & -1.589 \\
\hline 19 & L5 & 40 & 33.995 & -1.733 & 33.098 & -1.622 \\
\hline 20 & L5 & 42 & 34.011 & -1.747 & 32.939 & -1.611 \\
\hline 21 & L5 & 59 & 33.994 & -1.745 & 33.076 & -1.622 \\
\hline 22 & L5 & 45 & 33.720 & -1.730 & 32.331 & -1.577 \\
\hline 23 & L5 & 55 & 33.934 & -1.754 & 32.526 & -1.627 \\
\hline 24 & L5 & 39 & 33.383 & -1.770 & 32.022 & -1.610 \\
\hline 25 & L5 & 68 & 33.838 & -1.819 & 32.630 & -1.671 \\
\hline 26 & L5 & 47 & 33.464 & -1.759 & 31.888 & -1.611 \\
\hline 27 & - & $C N D$ & - & - & - & - \\
\hline 28 & - & $C N D$ & - & - & - & - \\
\hline 29 & L6 & 70 & 34.022 & -1.675 & 31.551 & -1.127 \\
\hline 30 & L6 & 70 & 34.056 & -1.633 & 31.863 & -1.348 \\
\hline 31 & L6 & 61 & 33.801 & -1.655 & 31.125 & -1.320 \\
\hline 32 & L6 & 73 & 34.006 & -1.664 & 31.556 & -1.482 \\
\hline
\end{tabular}




\begin{tabular}{|c|c|c|c|c|c|c|}
\hline 33 & L6 & 51 & 33.513 & -1.717 & 31.162 & -1.434 \\
\hline 34 & L6 & 46 & 32.992 & -1.675 & 30.677 & -1.489 \\
\hline 35 & L6 & 40 & 32.340 & -1.620 & 30.412 & -1.468 \\
\hline 36 & L6 & 44 & 33.242 & -1.739 & 30.896 & -1.532 \\
\hline 37 & L6 & 46 & 32.973 & -1.731 & 31.124 & -1.603 \\
\hline 38 & L6 & 75 & 34.020 & -1.706 & 32.116 & -1.597 \\
\hline 39 & - & 59 & 33.150 & -1.753 & 32.020 & -1.659 \\
\hline 40 & - & 44 & 32.557 & -1.673 & 30.467 & -1.254 \\
\hline 41 & - & 46 & 32.484 & -1.742 & 31.099 & -1.620 \\
\hline 42 & - & 39 & 32.494 & -1.712 & 31.246 & -1.651 \\
\hline 43 & - & 37 & 32.202 & -1.679 & 31.044 & -1.652 \\
\hline 44 & - & 52 & 32.384 & -1.693 & 31.357 & -1.668 \\
\hline 45 & L5.5 & 43 & 33.180 & -1.600 & 30.802 & -0.745 \\
\hline 46 & L5.5 & 51 & 33.897 & -1.659 & 31.681 & -0.435 \\
\hline 47 & L5.5 & $C N D$ & - & - & - & - \\
\hline 48 & L5.5 & 48 & 33.980 & -1.683 & 32.122 & -0.542 \\
\hline 49 & L5.5 & 63 & 34.234 & -1.571 & 32.615 & -0.603 \\
\hline 50 & L5.5 & 58 & 34.204 & -1.591 & 32.590 & -0.622 \\
\hline 51 & L5.5 & $C N D$ & - & - & - & - \\
\hline 52 & L5.5 & $C N D$ & - & - & - & - \\
\hline 53 & L5.5 & $C N D$ & - & - & - & - \\
\hline 54 & L5.5 & $C N D$ & - & - & - & - \\
\hline 55 & L5.5 & $C N D$ & - & - & - & - \\
\hline 56 & L5.5 & 50 & 33.867 & -1.776 & 32.323 & -1.124 \\
\hline 57 & L5.5 & 59 & 33.921 & -1.774 & 32.931 & -1.100 \\
\hline 58 & L5.5 & 63 & 33.961 & -1.766 & 32.750 & -0.674 \\
\hline 59 & - & 65 & 34.051 & -1.728 & 33.112 & -0.711 \\
\hline 60 & L5 & 62 & 33.986 & -1.762 & 32.831 & -0.674 \\
\hline 61 & L5 & 44 & 33.991 & -1.728 & 33.177 & -1.271 \\
\hline 62 & L5 & 44 & 34.000 & -1.737 & 33.045 & -1.000 \\
\hline 63 & L4 & $C N D$ & - & - & - & - \\
\hline 64 & L4 & $C N D$ & - & - & - & - \\
\hline 65 & L4 & 26 & 33.959 & -1.670 & 32.814 & -1.067 \\
\hline 66 & L4 & $C N D$ & - & - & - & - \\
\hline 67 & L4 & 42 & 34.297 & -1.688 & 33.673 & -1.421 \\
\hline 68 & L4 & 51 & 34.334 & -1.689 & 33.783 & -1.381 \\
\hline 69 & L4 & 46 & 34.353 & -1.716 & 33.739 & -1.404 \\
\hline 70 & L3 & 20 & 32.257 & -1.718 & 32.246 & -1.714 \\
\hline 71 & L3 & 15 & 31.864 & -1.718 & 31.864 & -1.719 \\
\hline 72 & L3 & $C N D$ & - & - & - & - \\
\hline 73 & L3 & $C N D$ & - & - & - & - \\
\hline 74 & L3 & 31 & 33.955 & -1.686 & 33.097 & -1.588 \\
\hline 75 & L3 & 22 & 34.040 & -1.683 & 33.327 & -1.517 \\
\hline
\end{tabular}




\begin{tabular}{|c|c|c|c|c|c|c|}
\hline 76 & L3 & 33 & 34.195 & -1.663 & 33.208 & -1.602 \\
\hline 77 & L3 & 48 & 34.322 & -1.681 & 33.715 & -1.560 \\
\hline 78 & L3 & 52 & 34.354 & -1.610 & 33.692 & -1.441 \\
\hline 79 & L3 & $C N D$ & - & - & - & - \\
\hline 80 & L3 & $C N D$ & - & - & - & - \\
\hline 81 & L3 & $C N D$ & - & - & - & - \\
\hline 82 & L2 & $C N D$ & - & - & - & - \\
\hline 83 & L2 & $C N D$ & - & - & - & - \\
\hline 84 & L2 & $C N D$ & - & - & - & - \\
\hline 85 & L2 & 54 & 34.309 & -1.385 & 33.709 & -0.538 \\
\hline 86 & L2 & 53 & 34.336 & -1.566 & 33.798 & -0.783 \\
\hline 87 & L2 & 42 & 34.370 & -1.545 & 33.711 & -0.567 \\
\hline 88 & L2 & 55 & 34.360 & -1.584 & 33.799 & -0.664 \\
\hline 89 & L2 & 51 & 34.392 & -1.623 & 33.825 & -0.995 \\
\hline 90 & L2 & 52 & 34.390 & -1.694 & 33.893 & -1.255 \\
\hline 91 & L2 & 58 & 34.405 & -1.723 & 33.800 & -1.410 \\
\hline 92 & L2 & $C N D$ & - & - & - & - \\
\hline 93 & L2 & 51 & 34.393 & -1.648 & 33.823 & -1.166 \\
\hline 94 & - & 87 & 34.420 & -1.770 & 34.014 & -1.624 \\
\hline 95 & - & 44 & 33.993 & -1.727 & 32.937 & -1.689 \\
\hline 96 & - & $C N D$ & - & - & - & - \\
\hline 97 & L1 & $C N D$ & - & - & - & - \\
\hline 98 & L1 & $C N D$ & - & - & - & - \\
\hline 99 & L1 & 85 & 34.366 & -1.795 & 33.925 & -1.647 \\
\hline 100 & L1 & $C N D$ & - & - & - & - \\
\hline 101 & L1 & 71 & 34.370 & -1.764 & 34.050 & -1.601 \\
\hline 102 & L1 & 58 & 34.367 & -1.719 & 34.004 & -1.460 \\
\hline 103 & L1 & 58 & 34.372 & -1.710 & 33.861 & -1.332 \\
\hline 104 & L1 & 66 & 34.390 & -1.705 & 33.995 & -1.409 \\
\hline 105 & L1 & 59 & 34.379 & -1.728 & 33.942 & -1.337 \\
\hline 106 & L1 & 30 & 34.363 & -1.547 & 33.654 & -0.659 \\
\hline 107 & L1 & 45 & 34.289 & -1.610 & 33.781 & -0.443 \\
\hline 108 & L1 & 45 & 34.292 & -1.589 & 33.737 & -0.198 \\
\hline 109 & SAT & $C N D$ & - & - & - & - \\
\hline 110 & SAT & $C N D$ & - & - & - & - \\
\hline 111 & SAT & 48 & 34.626 & -0.168 & 34.309 & 1.795 \\
\hline 112 & SAT & 43 & 34.583 & -0.213 & 34.245 & 1.788 \\
\hline 113 & SAT & 42 & 34.526 & -0.535 & 34.010 & 1.085 \\
\hline 114 & SAT & 38 & 34.337 & -1.411 & 33.769 & -0.176 \\
\hline 115 & SAT & 35 & 34.274 & -1.355 & 33.708 & 0.080 \\
\hline 116 & SAT & 39 & 34.322 & -1.321 & 33.626 & 0.141 \\
\hline
\end{tabular}




\begin{tabular}{|llllll|} 
ALL stations & 51 & 33.932 & -1.617 & 32.890 & -1.085 \\
SIM Branch stations & 50 & 34.370 & -1.475 & 33.825 & -0.719 \\
\hline
\end{tabular}

Table S2. Linear regression analyses (restricted to salinities $\geq 34.5$ ) of salinity- $\delta{ }^{18} \mathrm{O}$ measurements collected along transects occupied during the 2015. Slopes, intercepts, correlation coefficients (r) and associated standard errors (se) are reported for each transect.

\begin{tabular}{|ccccccc|}
\hline Transect & Slope & se & Intercept & se & Corrcoeff & Stations \\
SAT & 0.2243 & 0.0723 & -7.5502 & 2.5162 & 0.299 & $81-93$ \\
L2 & 0.4317 & 0.0418 & -14.8127 & 1.4567 & 0.7723 & $2-9 \& 78-79$ \\
L5 & 0.6056 & 0.0345 & -20.8911 & 1.1974 & 0.8454 & $10-24 \& 72-76$ \\
L6 & 0.572 & 0.0436 & -19.7179 & 1.5128 & 0.8763 & $27-38$ \\
165E & 0.7238 & 0.147 & -24.9681 & 5.1044 & 0.7017 & $39-54$ \\
175E & 0.5906 & 0.104 & -20.3403 & 3.6086 & 0.6777 & $56-71$ \\
\hline
\end{tabular}

Table S3. Linear regression analyses (restricted to the salinity range: $34 \leq \mathrm{S}<34.5$ ) of salinity- $\delta^{18} \mathrm{O}$ measurements collected along transects occupied during the 2015. Slopes, intercepts, correlation coefficients (r) and associated standard errors (se) are reported for each transect.

\begin{tabular}{|ccccccc|}
\hline Transect & Slope & se & Intercept & se & Corrcoeff & Stations \\
SAT & 0.3252 & 0.1944 & -11.0302 & 6.6668 & 0.5092 & $81-93$ \\
L2 & 0.3292 & 0.0839 & -11.2715 & 2.8837 & 0.5887 & $2-9 \& 78-79$ \\
L5 & 1.556 & 0.107 & -53.6881 & 3.6745 & 0.8267 & $10-24 \& 72-76$ \\
L6 & 1.3081 & 0.0716 & -45.0777 & 2.4549 & 0.9048 & $27-38$ \\
165E & 0.8079 & 0.0824 & -27.9041 & 2.8254 & 0.8499 & $39-54$ \\
175E & 1.1662 & 0.0746 & -40.239 & 2.5568 & 0.9472 & $56-71$ \\
\hline
\end{tabular}


Table S4. Linear regression analyses of salinity- $\delta^{18} \mathrm{O}$ measurements available from different data sets, including the North Pole Environmental Observatory (NPEO) [Alkire et al., 2015], Global Seawater Oxygen-18 Database [Schmidt et al., 1999], and Polarstern cruise ARK-XXI/2 [Bauch et al., 2011]. Slopes, intercepts, and correlation coefficients are reported for each data set. NPEO data were collected annually between 2000 and 2015 (no data from 2009) at latitudes $\geq 85^{\circ} \mathrm{N}$, primarily along longitudinal transects $90^{\circ} \mathrm{E}$ and $180^{\circ}$ [Alkire et al., 2015]. Measurements from the O-18 Database were restricted to latitudes $\geq 75^{\circ} \mathrm{N}$, and longitudes ranging between 65 and $160^{\circ} \mathrm{E}$ to best resemble the area studied in 2013. Further restrictions were applied, limiting the O-18 data to years after $2000(2000,2001,2007,2008)$ and then to $2007-2008$, to determine the impact (if any) on $\delta^{18} \mathrm{O}-\mathrm{S}$ relationships. ARK-XXII/2 data were similarly restricted to latitudes $\geq 75^{\circ} \mathrm{N}$ and longitudes $65-160^{\circ} \mathrm{E}$. A second longitudinal restriction $\left(110-160^{\circ} \mathrm{E}\right)$ was employed on the ARK-XXII/2 data to investigate the spatial dependence on the regression coefficients.

\begin{tabular}{|c|c|c|c|c|c|c|}
\hline Data Source & $\begin{array}{l}\text { Years } \\
2000-\end{array}$ & $\begin{array}{l}\text { Salinity } \\
\text { Range }\end{array}$ & Slope & Intercept & Corrcoef & $\mathbf{N}$ \\
\hline \multirow[t]{2}{*}{ NPEO } & 2015 & $S \geq 34.5$ & 0.6690 & -23.1220 & 0.7877 & 141 \\
\hline & & $34 \leq S<34.5$ & 1.1423 & -39.4408 & 0.6305 & 162 \\
\hline \multirow{7}{*}{$\begin{array}{c}\text { O-18 } \\
\text { Database }\end{array}$} & 1967- & & & & & \\
\hline & 2008 & $S \geq 34.5$ & 0.4618 & -15.8776 & 0.5191 & 1350 \\
\hline & & $34 \leq S<34.5$ & 0.8635 & -29.7775 & 0.6524 & 304 \\
\hline & $\begin{array}{l}2000- \\
2008\end{array}$ & $S \geq 34.5$ & 0.5401 & -18.5999 & 0.6571 & 606 \\
\hline & & $34 \leq S<34.5$ & 0.9234 & -31.8298 & 0.6757 & 153 \\
\hline & $\begin{array}{l}2007- \\
2008\end{array}$ & $S \geq 34.5$ & 0.6261 & -21.5984 & 0.7091 & 598 \\
\hline & & $34 \leq S<34.5$ & 0.9669 & -33.3287 & 0.7621 & 125 \\
\hline \multirow[t]{4}{*}{ ARK-XXII/2 } & 2007 & $S \geq 34.5$ & 0.3749 & -12.9036 & 0.5923 & 104 \\
\hline & & $34 \leq S<34.5$ & 0.2478 & -8.6570 & 0.2219 & 113 \\
\hline & $\begin{array}{c}110- \\
160^{\circ} \mathrm{E} \\
110-\end{array}$ & $S \geq 34.5$ & 0.3796 & -13.1062 & 0.4748 & 24 \\
\hline & $160^{\circ} \mathrm{E}$ & $34 \leq S<34.5$ & 0.5205 & -18.0897 & 0.5868 & 59 \\
\hline
\end{tabular}




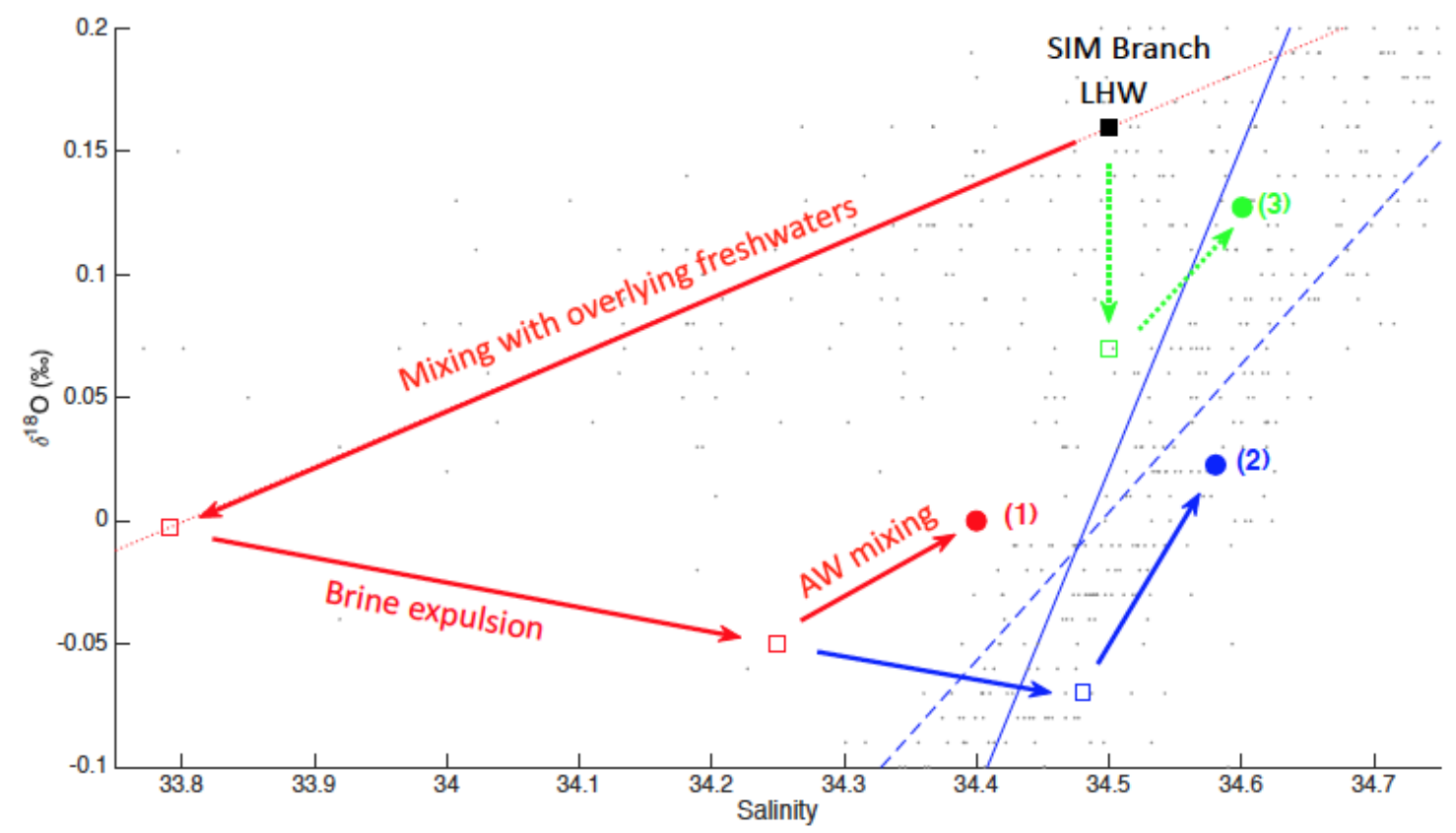

Figure S1. Schematic of the transition of lower halocline waters from the SIM branch to the MW branch via mixing with overlying freshwaters, salinization through sea ice formation/brine release, and mixing with Atlantic waters (AW). The red pathway illustrates the effect of vertical mixing down to $50 \mathrm{~m}$ (the mean winter mixed layer depth at SIM branch stations), brine expulsion due to the formation of $1 \mathrm{~m}$ of sea ice, and mixing with AW in a 21:79 ratio to form lower halocline water with a salinity of 34.4 and $\delta^{18} \mathrm{O}$ of $0 \%$ (1). The blue pathway deviates from the red pathway due to additional ice formation $(1.5 \mathrm{~m}$ instead of $1 \mathrm{~m})$ to form lower halocline water with a salinity of 34.58 and $\delta^{18} \mathrm{O}$ of $0.02 \% 0$ (2). The green pathway illustrates the effect of vertical mixing to $100 \mathrm{~m}, 1 \mathrm{~m}$ of sea ice formation, and AW mixing to form lower halocline water with a salinity of 34.6 and $\delta^{18} \mathrm{O}$ of $0.13 \%$ (3). The regression lines representing the SIM branch (red, dotted line), upper MW branch (blue, dashed line), and lower MW branch (blue, solid line) are also shown for reference. The gray dots indicate data collected during the 2013 cruise. Empty squares indicate transition points after each step (freshwater mixing, brine expulsion, and AW mixing) whereas filled circles indicate the final halocline water product formed by the three potential pathways. All three pathways yield salinity and $\delta^{18} \mathrm{O}$ combinations near (but not directly on) the MW mixing branches, indicating some additional processes and/or mixing (such as freshwater influence from river runoff) takes place during the transition from the SIM branch to the MW branch. 


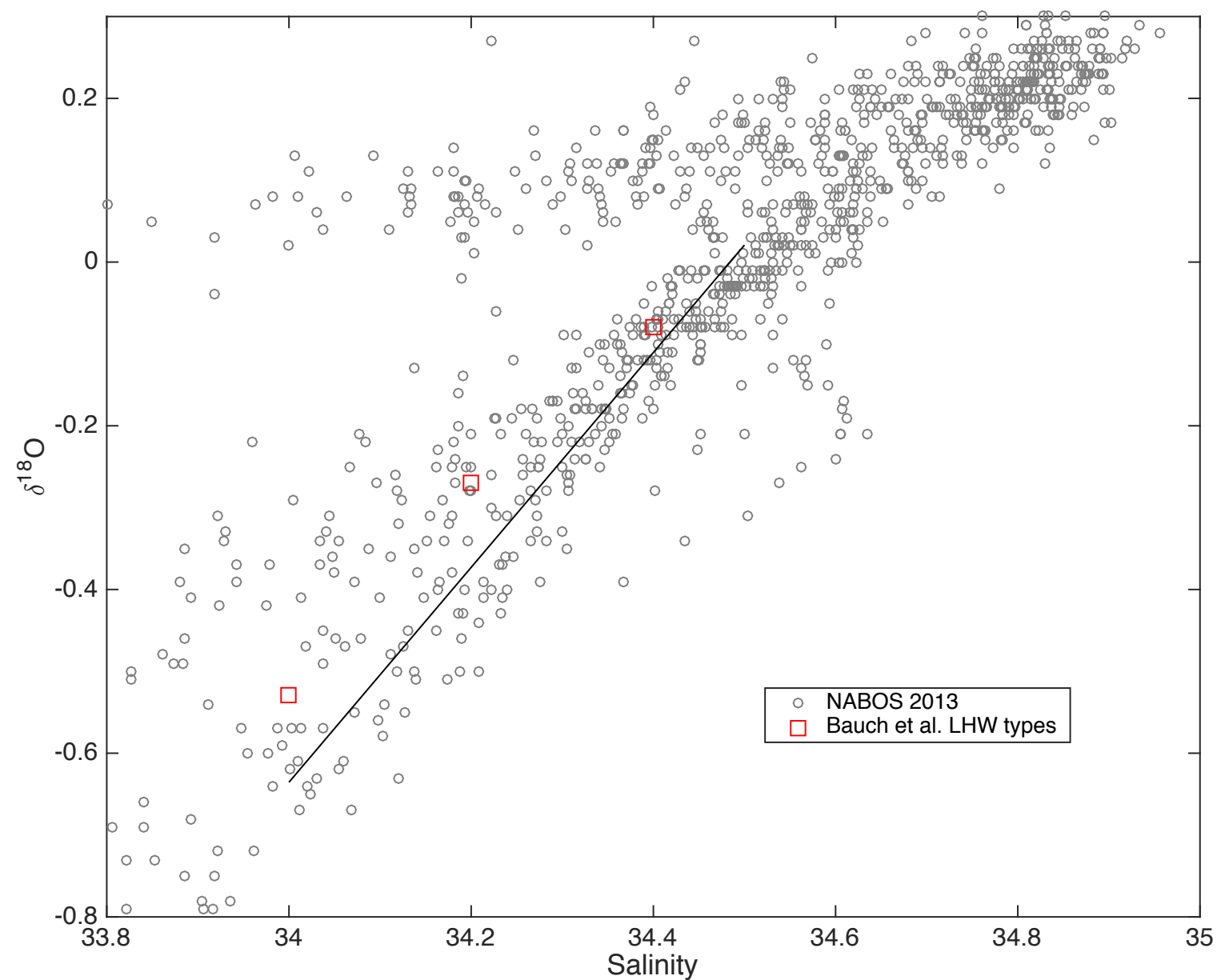

Figure S2. Plots of salinity versus the stable oxygen isotopic ratio $\left(\delta^{18} \mathrm{O}\right)$ measured during the 2013 cruise (gray circles) and characteristic values for the $\mathrm{c} 2\left(\mathrm{~S}=34, \delta^{18} \mathrm{O}=\right.$ $0.53 \%), \mathrm{c} 3\left(\mathrm{~S}=34.2, \delta^{18} \mathrm{O}=-0.27 \%\right)$, and $\mathrm{c} 4\left(\mathrm{~S}=34.4, \delta^{18} \mathrm{O}=-0.08 \%\right)$ lower halocline water (LHW) water types (red squares) defined in Bauch et al. [2016]. The c1 LHW type $\left(\mathrm{S}=33.0, \delta^{18} \mathrm{O}=-1.46 \%\right.$ ) is not shown. The linear regression defining the lower MW branch $\left(\delta^{18} \mathrm{O}=1.3126^{*} \mathrm{~S}-45.2639\right)$ is included as a black, solid line. Note that a separate linear regression of the values characterizing the four LHW types was $\delta^{18} \mathrm{O}=0.9828 * \mathrm{~S}-33.901$. 

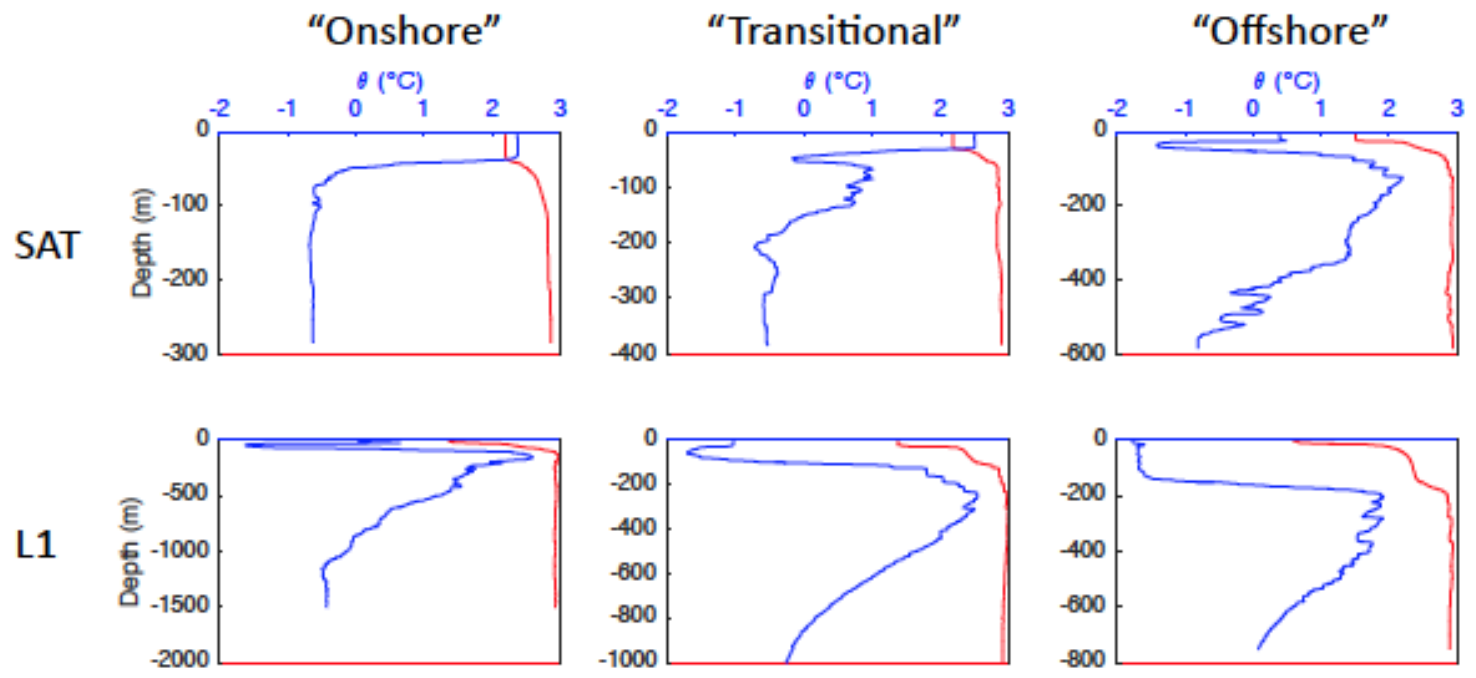

L2
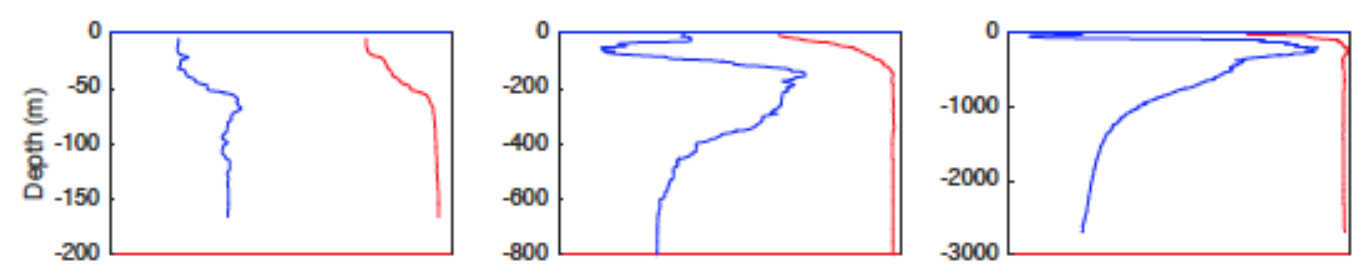

L3
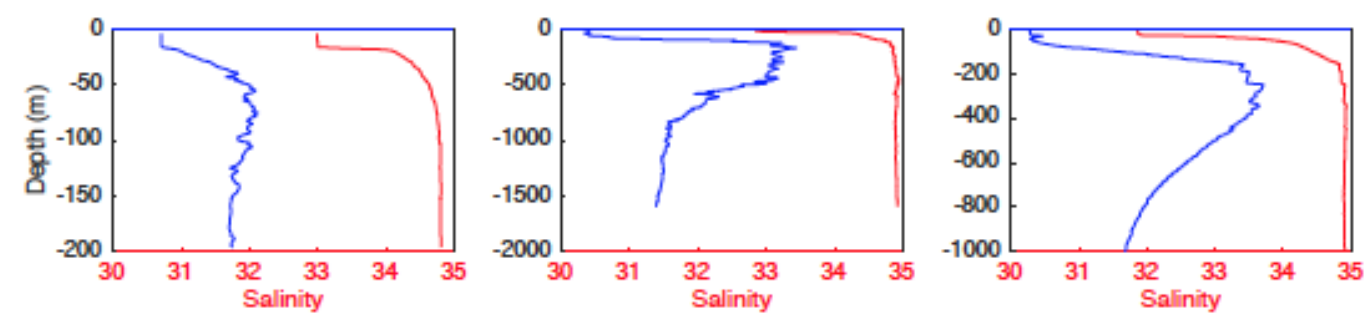

Figure S3. Vertical profiles of potential temperature $(\theta)$ and salinity plotted as blue and red lines, respectively, for selected stations on the SAT, L1, L2, and L3 transects. Stations were selected that generally represented the hydrographic conditions observed nearest the continental shelves ("onshore"), on the slope ("transitional"), and in the deep basins (offshore) along each transect. Note that, while the temperature and salinity axes are identical among panels, the range of the y-axes (depth) varies with each panel. 
"Onshore"

L4
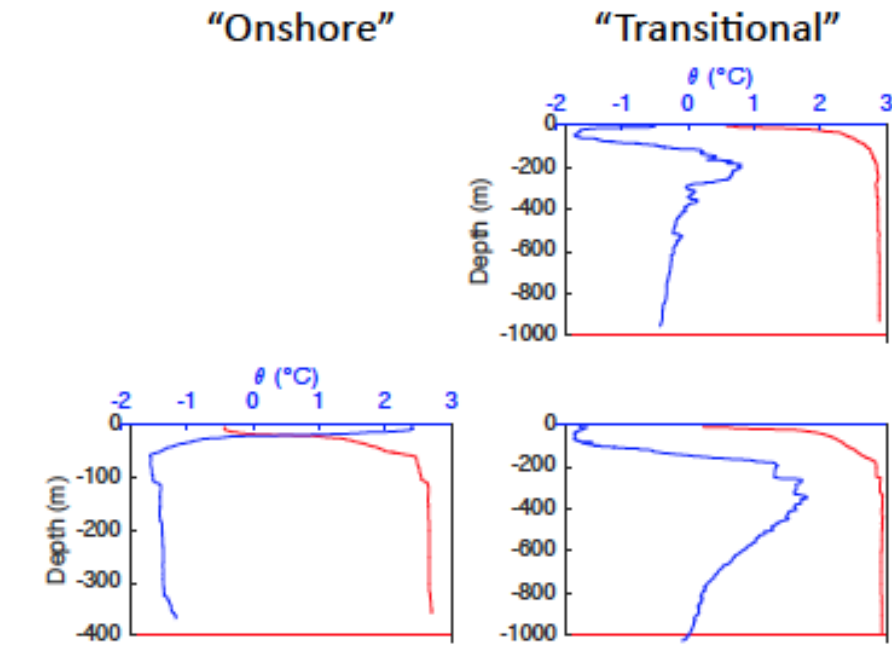

L5
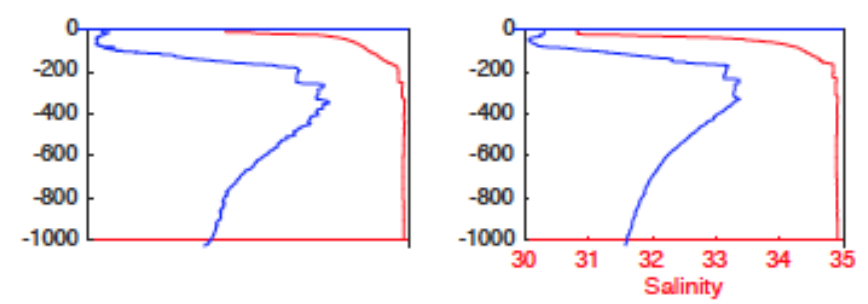

L5.5
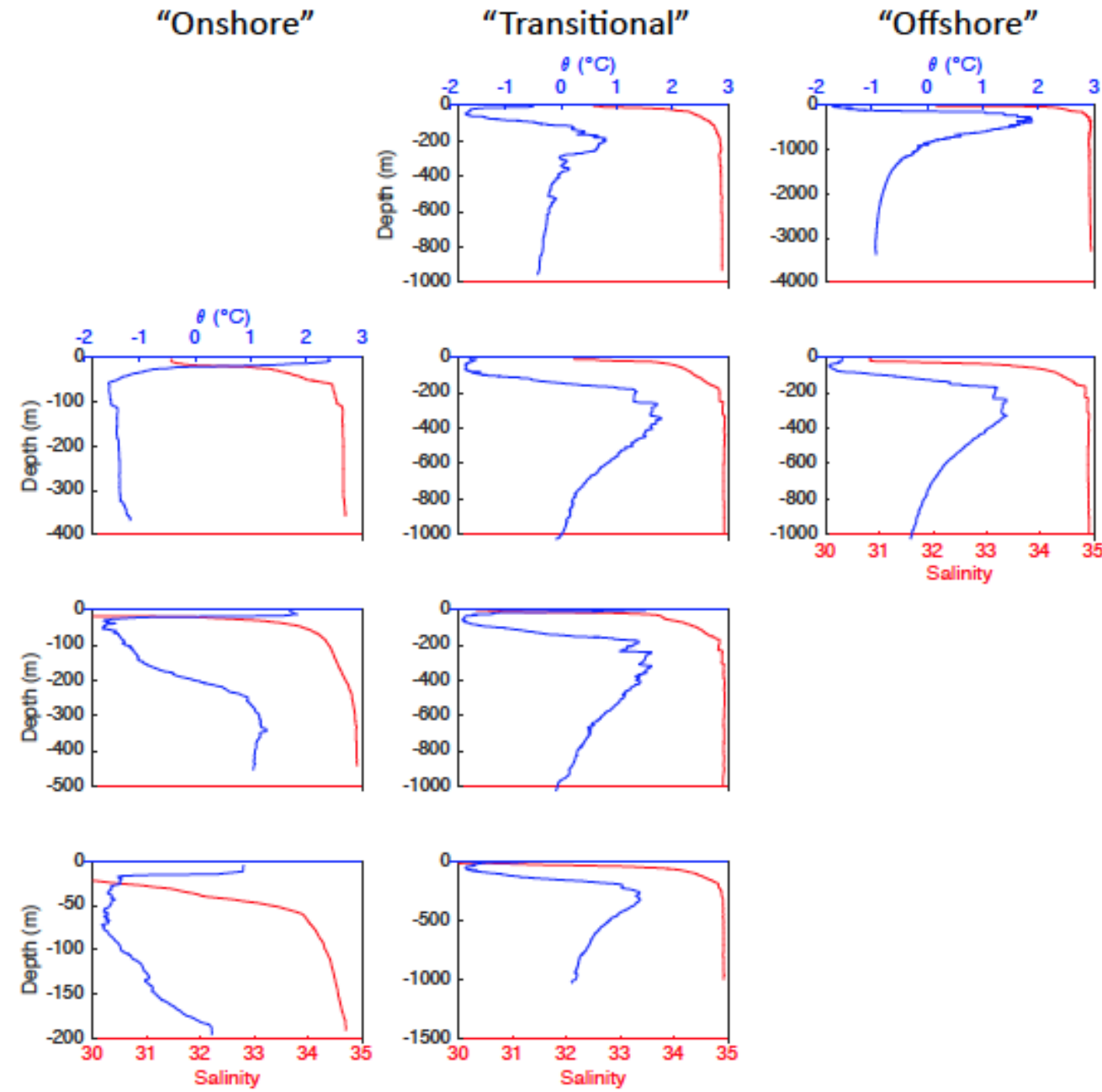

L6

Figure S4. Vertical profiles of potential temperature $(\theta)$ and salinity plotted as blue and red lines, respectively, for selected stations on the L4, L5, L5.5, and L6 transects. Stations were selected that generally represented the hydrographic conditions observed nearest the continental shelves ("onshore"), on the slope ("transitional"), and in the deep basins (offshore) along each transect. Note that, while the temperature and salinity axes are identical among panels, the range of the y-axes (depth) varies with each panel. 